\title{
Development of a Front Limb Support to Facilitate Weight Reduction in Horses with Ambulatory Difficulties
}

\author{
Samantha Steinke \\ University of Saskatchewan \\ Brent Roberts \\ RMD Engineering \\ James Boire \\ RMD Engineering \\ Julia Montgomery ( $\nabla$ julia.montgomery@usask.ca ) \\ University of Saskatchewan
}

\section{Research Article}

Keywords: horse, weight reduction, ambulatory support, rehabilitation lift, biomedical device design

Posted Date: March 2nd, 2022

DOI: https://doi.org/10.21203/rs.3.rs-1376565/v1

License: (9) This work is licensed under a Creative Commons Attribution 4.0 International License. Read Full License 


\section{Abstract}

In horses, severe limb injuries and other problems affecting ambulation are challenging to manage. Offloading the injured limb can result in secondary complications such as supporting limb laminitis (SLL), severely affecting quality of life and sometimes necessitating euthanasia. SLL results from increased load and decreased blood flow to the foot.

There is a need to develop a dynamic device to reduce the load on the limbs while maintaining mobility and blood flow for the rehabilitation of horses with ambulatory difficulties. In this study, the unique biomechanics of the horse were considered in the design of a dynamic front limb weight support system. The development further had to consider complications associated with its use, such as pressure ulcers and other tissue trauma. Therefore, the design included silicone air pockets to be inflated and deflated in a programmable cycle. A series of three prototypes resulted in a front limb support (breastplate) intended for use with a computer-controlled rehabilitation lift. Iterative design modifications of the breastplate allowed to safely provide up to $50 \%$ front limb weight reduction while maintaining horse comfort. This is a significant step towards adjustable, dynamic ambulatory support with the ability to customize rehabilitation programs for horses with ambulatory difficulties.

\section{Introduction}

Musculoskeletal injuries are common in equine athletes and secondary problems can develop during injury recovery [1-4]. Rehabilitation of horses is complicated by their size, weight (average sized horse, $500 \mathrm{~kg}$ ) and behavioural flight response. The most severe complication is supporting limb laminitis (SLL), [5] resulting from overloading and ischemia in healthy $\operatorname{limb}$ (s) subsequent to reduced weight-bearing on the injured limb. Gardner et al. (2017) [2] have reported a mortality rate between 50-75\% once SLL develops. Therefore, complications need to be prevented for the best chance at successful rehabilitation.

Horses cannot remain in recumbency for extended periods due to adverse physiological consequences on their respiratory system, hindered blood flow to their muscles and possible nerve damage [6]. Many attempts have been made to develop a device to reduce or avoid weight bearing during periods of ambulatory difficulty ([7-9], reviewed by Steinke et al., (2021) [10]). In response to continued challenges, a new dynamic support system is under development [11]. This study focuses on the development of the front limb support (breastplate) of horses, intended for use together with a dynamic rehabilitation lift [12]. A properly designed support system of the front limbs is particularly crucial because standing horses bear $60 \%$ of their weight on the front limbs [13].

\section{Objective}

The aim of this study was to design and prototype a breastplate lined with air pockets that could alternate pressure and allow for intermittent pressure relief and drying of the underlying skin. The 
objective was to develop a breastplate that could be comfortably worn by a horse with up to $50 \%$ load reduction applied by a dynamic rehabilitation lift.

\section{Methods}

Three consecutive prototypes were developed to address the objective. The first prototype was made of fibreglass and silicone air pockets with complete control of each individual air pocket. The design principle of prototype I was to build a strong structure capable of supporting horses while moulded to their body shape. Prototypes II and III built on these principles, while improving flexibility for horse comfort. Since these subsequent prototypes were developed based on results obtained from prototype testing, they are described in section 4.

\subsection{Prototype I}

Prototype I was a flexible fibreglass shell (resin from Pro Form Products Ltd., Ontario, Canada, [PF175]) and fibreglass cloth (Stage 2). Its rigidity was increased with the addition of auto body filler (PF164) (Pro Form Products Ltd., Ontario, Canada) and integration of a steel support frame into the fibreglass for attachment to the lift. The fibreglass shell was filled with 221 individual silicone (Dragon Skin ${ }^{\mathrm{TM}} 30$, Smooth-On, Inc., Macungie, PA) air pockets. Silicone was chosen because of its use in other pneumatic air actuators [14-16] and it is deemed medically safe and compliant for use in humans [15]. Silicone has superior physical properties and flexibility, a shore hardness value of $30 \mathrm{~A}$, tensile strength of $500 \mathrm{psi}$, a $100 \%$ Modulus of 86 psi, and an elongation @ break value of 364\% [17]. Cyclic inflation and deflation of air pockets is intended to relieve pressure intermittently, allowing for the return of blood flow and drying of the skin. The silicone air pockets were tested to failure to determine the maximum psi (10 psi). A 60second cycle was used for prototype I with intent to maintain maximum blood flow in vertical pressure areas while maximizing surface area providing horizontal support (upward lift). Cycles vary throughout the literature (e.g., 1-in-2 cycle (alternating), 1-in-4 cycle [18-19]), and therefore, would need to be determined through testing. This testing would consist of a multifactorial analysis - pressures resulting in capillary closure, the time before tissue damage occurs, and time for blood flow to return to the area for horses, which was not a part of this design study.

Prototype I would require customization for each horse due to the rigid fibreglass structure. Prototypes II and III were developed based on prototype I testing as described in section 4. Materials used in the prototypes are summarized in Table 1. 
The main components of each breastplate prototype.

\begin{tabular}{|c|c|}
\hline $\begin{array}{l}\text { Prototype } \\
\text { Number }\end{array}$ & Components of Prototype \\
\hline \multirow[t]{9}{*}{ Prototype I } & Fibre-glass shell \\
\hline & Autobody Filler \\
\hline & Metal plate support \\
\hline & Solenoids \\
\hline & Pressure gauges \\
\hline & Air manifolds \\
\hline & Individual air lines \\
\hline & Individual air pockets (221) \\
\hline & Arduino \\
\hline \multirow[t]{2}{*}{ Prototype lla } & Metal plates connected via seat-belt webbing embedded in silicone \\
\hline & Four sections of air pockets \\
\hline \multirow[t]{2}{*}{ Prototype llb } & Metal plates connected via seat-belt webbing embedded in silicone \\
\hline & Four sections of air pockets \\
\hline \multirow[t]{3}{*}{ Prototype III } & $\begin{array}{l}\text { Woven polyester scrim coated with PVC (Polyvinyl chloride) (P911 Mesh [MSP911_ } \\
\text { _100] embedded in silicone }\end{array}$ \\
\hline & Four sections of air pockets \\
\hline & Four metal triangle attachments for the $\mathrm{H}$-frame/lift \\
\hline
\end{tabular}

\subsection{Testing model}

Initial tests with the breastplate were completed on a Styrofoam horse model. Fit testing was a multi-step process, including measuring material templates on both the model horse and research horse and creating a three-dimensional (3D) model from a spray foam mould of the model horse. Once the 3D model had been created, Styrofoam templates were cut out to measure the research horse's shape and proper curvature. Using the measurements obtained from the Styrofoam fitting templates, a Styrofoam mould was milled to replicate the shape of the research horse to build prototype I. Safety testing included load testing where the model horse was loaded with metal weights. In cases where a live test was required (fit, comfort, weight compensation), the research horse was used.

\subsection{Weight compensation lift}

A computer-controlled dynamic rehabilitation lift system with adjustable weight compensation (i.e., incremental load reduction) was used for weight compensation trials (lift previously described in [12]). To 
reduce the load by $50 \%$ on the forelimbs, $150 \mathrm{~kg}$ would need to be supported by the lift in a $500 \mathrm{~kg}$ horse which carries $60 \%(300 \mathrm{~kg})$ of its bodyweight on the front limbs. A $50 \%$ weight reduction was the aim of this research because if a horse completely transfers the weight usually borne by two limbs onto one limb, a 50\% weight reduction would restore the load normally borne by each limb. Furthermore, other studies have shown that a $75 \%$ weight reduction can result in muscle atrophy $[7,20]$ and therefore is likely excessive. It is essential to remove enough weight that blood flow can be maintained, but also not to remove too much weight and cause muscle atrophy or, in severe cases, wasting or osteopenia.

\subsection{Research horse used for testing}

The horse used for breastplate design and testing was a 23-year-old Thoroughbred mare. Only one horse was used to maintain safety for both the horse and handlers by using a horse familiar with the dynamic weight compensation lift used in similar trials preceding this phase of the research program. The horse was a research horse explicitly acquired for testing the harness and lift. Therefore, it was familiar with the harnesses and weight compensation testing procedures. The study was approved by the University of Saskatchewan's Animal Research Ethics Board and adhered to the Canadian Council on Animal Care guidelines for humane animal use (AUP \#20140059) and is reported in accordance with ARRIVE guidelines.

\subsection{Weight compensation trials}

For each weight compensation trial, the breastplate was applied to the horse, and the horse was allowed to acclimatize to the new conditions. The horse was then attached to the weight compensation lift. Weight compensation in the front was increased by $10 \mathrm{~kg}$ increments, and behavioural and physiological observations were noted as previously described [12]. If complications were observed, trials were terminated, and breastplate design modifications were made before continuing. Trials were short-term (up to 1 hour) focused on obtaining a $50 \%(150 \mathrm{~kg})$ weight reduction.

\section{Results}

\subsection{Prototype I}

\subsubsection{Strength and Fit Testing}

The breastplate was strength tested under a $227 \mathrm{~kg}$ load (> than desired $150 \mathrm{~kg}$ for safety margin) and tested for inflation and deflation of air pockets under loading. Complications included the separation of materials, the breastplate sliding forward, twisting with the cycling of air pockets and a lack of flexion in the breastplate. Design modifications (a more flexible structure, better bonding of silicone to supporting material to seal air pockets to hoses, and a way to keep the breastplate from sliding forward) were needed. Details of complications, the knowledge gained, and implemented solutions are summarized in Table 2. 
Table 2

Complications observed, knowledge gained, and design solutions for breastplate design obtained during initial material testing of prototype I.

\section{Complication \\ Knowledge Gained \\ Design Solution}

Breastplate moves forward and twists under hoist
Weight and cycling of air pockets caused breastplate to slide forward and Styrofoam mould to slide back. This could cause the horse to slip out of the breastplate. Air pockets on an angle along with force acting backwards during the inflation/deflation cycle walks the object backwards in the breastplate.

Height/Shape of air Square air pockets do not inflate enough to fill pockets gaps between the horse and the breastplate.
No cycling of air pockets on an angle (on the chest area not directly under horse) or no air pockets, just padding in these areas.

Different shape/more stretch for next design or more flexible breastplate shell to increase contact area.

Little flex in the breastplate
Need flex in breastplate to follow contours, so all air pockets make contact. This also became an issue with fit to a specific horse and weight gain or loss, which causes their shape to change. Although rigidity does make it easier to handle and place on the horse.
More flexible structure/support for the breastplate. Some rigidity to shape to the horse to make it easier to apply and eliminate need for customization to each horse.

Leakage of air pockets

Each pocket individually sealed to hose with
Air pockets that were sealed develop leaks with use. Even causing leaks through Velcro and silicone above fibreglass when silicone air pockets were attached and sealed to the fibreglass via adhesive Velcro bonding. mechanical versus a chemical bond-use of a nut/clamp to attach silicone to the hose. reduce components and change. Cannot adjust the shape/size/contour easily with all air pockets and components

Force backwards pulls air pocket back. When the air pocket deflated that force is removed from the air pocket. When the air pocket reinflated straight up versus pulled back like previously, object in breastplate moved and twisted. Need more inflation/deflation to circulate air.
Simplify breastplate, weight.

When fitting to the horse, it is not a simple attached.

Heavy and difficult to place on a horse.

With less components can cut to fit and adjust after testing and complications arise.

Change in air pocket design to prevent backwards force and allow for better airflow.
Compression of air pockets* 


\subsubsection{Modifications}

Design modifications were made to address the complications presented in Table 2. Different materials were tested (e.g., Velcro, fleece, silicone, seatbelt webbing and standard weaved webbing straps). The loop side of the adhesive silicone was found to be the best for attachment to the silicone and the fibreglass. Therefore, the silicone was removed from the fibreglass, the entire fibreglass shell was lined with adhesive Velcro, and the silicone air pockets were re-attached, but separation between air pockets was still observed. Due to rigidity of the fibreglass, the breastplate did not fit tightly to the horse. A new material was needed to better bond silicone and provide greater flexibility in the support material.

\subsection{Prototype II}

\subsubsection{Development}

Prototype II was made of aluminium plates for strength connected via nylon webbing for better flexibility to align with the body shape of the horse. The silicone air pockets were poured in moulds containing 72 air pockets in three pieces to allow for air flow between layers. This further allowed for four sections to be placed on the supporting metal plates rather than attaching individual air pockets. The reduction of air lines significantly reduced the thickness of the breastplate and its weight. The deflated air pockets were staggered throughout the breastplate to maintain even contact. Therefore, fewer manifolds and components were needed to control airflow. This reduced complexity also reduced the number of silicone pours and separate components that needed to be glued together with silicone. Three moulds (a top mould that included air pockets, a middle mould that included the airlines and a bottom mould sealed in the air lines) were used to create one usable set of air pockets, and only four sets were required to cover the breastplate.

\subsubsection{Strength and Fit Testing}

The breastplate was strength tested under a $227 \mathrm{~kg}$ load for inflation and deflation of air pockets. A twohour comfort trial was performed to test the fit on the research horse. The breastplate placed significant pressure on the inside and back of the horse's front legs. This pressure on the inside of the legs resulted in significant bunching of the skin around the breastplate, forcing the breastplate into a slight ' $v$ '. Complications observed and resultant modifications (leading to prototype Ilb) are summarized in Table 3. 
Table 3

Complications observed, knowledge gained, and design solutions for breastplate design obtained during trials with Prototype lla using research horse not attached to weight compensation lift.

Complication $\quad \begin{aligned} & \text { Knowledge Design Solution } \\ & \text { Gained }\end{aligned}$

Significant pressure on insides of legs visually determined through displacement and bunching of skin and hair, Vshape of breastplate and spreading of the legs.

Significant pressure on the back of legs (elbow) visually determined through displacement and bunching of skin and hair.

Limited flex in breastplate resulting in gaps behind the elbow and digging into the abdomen at the back of the abdomen piece.
Breastplate sternum piece is too wide for the research horse.
Trimming the width of the sternum piece to allow gaps between insides of legs and breastplate.

\section{Breastplate slides forward, and the abdomen piece placed pressure on elbows.}

Not enough flex in breastplate to follow contours of the horse, so all air pockets make contact.
More flexible structure/support for the breastplate. Horizontal flex and vertical flex need to increase so that the breastplate can follow the curvature of the chest and abdomen, maximizing the contact area and maintaining even contact.

Different support material with no rigid structures.

Weight of breastplate

Heavy and difficult to place on a horse.

Time to fix/build

Metal plates
cannot be easily
cut to make
modifications
requiring
downtime.

Further simplify breastplate, reduce components and weight.

Find a material that is easily cut or trimmed to make modifications-a material not requiring special equipment to modify.

\subsubsection{Modifications}

With prototype Ilb, several modifications were made to improve horse comfort, reducing air pockets to three per row to allow for more space between the legs and behind the shoulder (at the point of the elbow). The main pressure points were between the legs and behind the elbow, pushing into the elbow from the back, visually determined through displaced and bunching skin, as well as spreading of the legs.

The rigidity of this prototype did not allow for enough flexibility behind the shoulder to adjust for the curvature of the trunk. The side-to-side flexibility of the section sitting behind the shoulder needed to be 
modified before building the next prototype (addressed in prototype III below). The circumference of the horse's abdomen gained one inch with every inch moved further backwards. This curvature highlights the need to have side to side (horizontal when placed on the horse) as well as up and down flexibility (vertical when placed on the horse) to increase the surface contact area. Increasing the flexibility would reduce the need for customization between horses allowing for one breastplate to fit a broader range of horses and adjust to their changing shape when moving.

Another comfort and fit trial (two hours) was completed with prototype llb, allowing the horse to get used to wearing the modified breastplate. The horse seemed to be comfortable for the entire two hours the breastplate was worn. However, complications during testing with the weight compensation lift using the model horse (Table 4) led to further design modifications and development of prototype III. 
Table 4

Complications observed, knowledge gained, and design solutions for breastplate design modification during lift testing trial with Prototype llb using the model horse attached to weight compensation lift.

\section{Complication}

Significant pressure on the back of legs (elbow) visually determined through tight contact with the model horse's leg.

\section{Gap at sternum} between breastplate and horse
Knowledge Gained

Breastplate slides forward, and the abdomen piece placed pressure on the elbows.
Design Solution

New support material needed with greater flexibility to follow the contours of the horse.
Gap at the sternum, which could result in greater "squeezing" in on the abdomen.

\section{Complete} depression of air pockets at the back of the abdomen piece.
Not enough flex to follow contours of horse.

Pressure needs to be removed from the sides of the abdomen, "squeezing" inward on the model horse, directing straps up and out versus up and in.

Limited flex in breastplate resulting in gaps behind the elbow.
Not enough flex in breastplate to follow contours of the horse, so all air pockets make contact, even with weight compensation.

The solid metal pieces could cause injury to the horse if displaced in an emergency.
More horizontal flex to follow the contour of the abdomen.

Extension of the middle bar of the $\mathrm{H}$-frame attaching breastplate to weight compensation lift.
Greater flexibility in the support material.
There could be interference with the horse's leg when moving forward due to the placement of the breastplate.
Possible interference with legs moving forward.

\subsection{Prototype III}

\subsubsection{Design and Development}

The third and current prototype (Fig. 1) was made from woven polyester scrim coated with PVC (Polyvinyl chloride) (P911 Mesh [MSP911__ 100] obtained from Michel's Industries, St. Gregor, SK) as weight supporting material in the breastplate to increase the flexibility of the structure. The webbing was 
incorporated into the silicone and attached to the air pockets. Steel lifting loops were sewn into the webbing to attach the breastplate to the lift. This change in material allowed for a better fit, potentially reducing the need for customization between individual horses. It also allowed the breastplate freedom to move with the horse to increase comfort. This added flexibility with the new supporting material made a significant change in comfort for the research horse allowing for $50 \%$ weight reduction during testing.

\subsubsection{Strength and Fit Testing}

Prototype III was again tested to $227 \mathrm{~kg}$. The air pockets were then fully inflated and checked for any leaks (Fig. 1).

The breastplate was fitted to the research horse to ensure the horse was comfortable in the breastplate. Safety straps were added to the breastplate to attach the breastplate to the horse before attachment to the lift. This addition of straps also allowed the breastplate to be worn without attachment to the lift for fit tests. The horse did not display any discomfort while walking. The horse appeared relaxed, and no change in behaviour was observed. The air pockets were then tested for inflation.

\subsubsection{Testing with weight compensation}

The breastplate fit well, and the horse seemed comfortable up to $100 \mathrm{~kg}(33 \%)$ of weight reduction during the first weight compensation trial (Fig. 2).

Flexibility had significantly improved with the new material. However, the breastplate appeared to be sliding forward once weight compensation was applied, placing more pressure against the point of the elbow and triceps. A breeching strap was added as a design modification to hold the breastplate in place.

The following weight compensation trial with prototype III involved adding the breeching strap to keep the breastplate back and away from the elbow (Fig. 3).

Observations were made at each $10 \mathrm{~kg}$ increment. After the weight reduction goal was reached $(150 \mathrm{~kg}$ or $50 \%$ weight reduction), the weight reduction was incrementally decreased. The total trial time was approximately 30 minutes.

The addition of the breeching strap held the breastplate in place and did not place pressure on the elbows. There were only slight postural changes as the weight increased, including changes between resting of the hind legs and shifting of weight. The horse remained relatively comfortable up to the goal of $150 \mathrm{~kg}$ of weight reduction. It was suggested to move the breeching strap higher in the next trial for better placement, placing pressure higher up, closer to the tail due to the forward placement of the hind legs during lifting, which was completed in the next trial. Again, the weight compensation was increased in $10 \mathrm{~kg}$ increments and observations were made at each increment. The quick release was tested in this trial to ensure the horse could be detached quickly in an emergency with a $50 \%$ weight compensation load (150 kg) on the buckles. 50\% weight compensation was achieved (and held for five minutes) without significant discomfort or aversion behaviours. The breastplate seemed to stay in place, with the breeching strap holding it back from the elbow. The breastplate was pulled further back at the beginning 
of the trial, which seemed to be a better placement of the breastplate during lifting. Total trial time was 43 minutes.

\section{Discussion And Conclusion}

This design study describes several breastplate prototypes for front limb support of horses attached to a dynamic rehabilitation lift that enables incremental weight reduction. The study was part of a multi-phase research program developing an equine rehabilitation lift and support system for controlled weight reduction. The objective was to design and test an air-pressurized breastplate for front limb support of a horse. Front limb injuries tend to be more common [21], and a higher ratio of weight is supported by the front limbs [13]. This breastplate is to be used in combination with a dynamic weight compensation lift. The objectives of the current project phase were met through design and modifications to a breastplate to support the front limb weight of a horse to ensure it could safely support $50 \%$ of the horse's front limb weight.

The breastplate evolved from a rigid fibre-glass shell to a flexible, loose-webbed material. Through problem-solving, research, and prototype design improvements, a more functional, practical device was developed. The first prototype (prototype I) consisted of a solid fibre-glass structure, lined with silicone air pockets (providing soft cushioning), customized to the research horse's shape. To improve flexibility and reduce complexity, while maintaining material strength, prototype II was made of metal plates connected via seatbelt webbing, integrated into silicone, and lined with air pockets. Prototype III, was made of a woven polyester mesh, integrated into silicone, and lined with air pockets. This prototype has excellent flexibility, following the curvature of the chest and abdomen, and moves with the horse. With the achievement of comfort in the research horse trials were able to proceed to short-term (30 minutes to 1 hour) weight compensation testing with up to $50 \%$ weight reduction.

There were several limitations associated with this study, including the use of only one horse. Knowledge was gained as each additional component was added and design modifications were made. As expected, multiple design iterations were needed to create a flexible yet strong design that can be comfortably worn by a horse and enable up to $50 \%$ weight reduction while maintaining mobility. Difficulties in bonding silicone to support materials, finding materials strong enough to support a horse while also allowing for attachment of support straps, air pockets, and flexibility to fit a range of horses was challenging. Suggestions for the next phase include minor modifications to the current breastplate prototype, including an $X$ shape with straps on angles to further remove pressure from the shoulders and elbow by pulling out and away. A new silicone mould will have to be created with an X-shape to encase the webbing in silicone.

In conclusion, the breastplate shows great promise for use in equine rehabilitation. The objectives accomplished include the design and development of the initial prototype breastplate for supporting the front limbs during weight reduction. The breastplate design described in this study is a significant step 
towards developing a support harness for equine rehabilitation that can be used together with a dynamic rehabilitation lift.

\section{Declarations}

\section{Acknowledgements}

The authors would like to acknowledge the help of Dr. Jennifer Abi Younes with the weight compensation trials.

\section{Funding}

This work was supported by Mitacs Accelerate awarded to Dr. Julia Montgomery (grant number IT11322); the College of Engineering Centennial Scholarship Fund, University of Saskatchewan, College of Engineering awarded to Samantha Steinke; and the Russell (Russ) William Haid Memorial Award awarded to Samantha Steinke.

\section{Author Contributions}

This study was part of SLS Master of Science thesis in biomedical engineering. SLS was supervised by JBM. The rehabilitation lift used in the study was designed and built by RMD Engineering. All authors contributed to the study conception and design. The breastplate prototypes described in this manuscript were designed and built by RMD (JRB and BR). Safety testing was completed at RMD. Testing with the horse and data collection during weight compensation trials was completed by SLS and JBM, with support from BR. Design modifications were made by RMD based on discussions among all authors, following each prototype testing. The first draft of the manuscript was written by SLS. All authors reviewed and commented on each version of the manuscript. All authors read and approved the final manuscript.

\section{Competing interests}

The authors declare no competing interests.

\section{Data availability}

A detailed description (with pictures) of all design steps and testing data are available in the following M.Sc. thesis: S.L. Steinke, 2021. Biomechanics in equine rehabilitation: a weight-reduction system and movement tracking device. M.Sc. Thesis. Saskatoon: University of Saskatchewan, 190 pp.

\section{Ethics approval}

The study was approved by the University of Saskatchewan's Animal Research Ethics Board and adhered to the Canadian Council on Animal Care guidelines for humane animal use (AUP \#20140059) and is reported in accordance with ARRIVE guidelines. 


\section{References}

1. Baxter, G.M., \& Morrison, S. (2008). Complications of Unilateral Weight Bearing. Veterinary Clininics of North America - Equine Practice, 24, 621-642. https://doi.org/10.1016/j.cveq.2008.10.006

2. Gardner, A.K., van Eps, A.W., Watts, M.R., Burns, T.A., \& Belknap, J.K. (2017). A novel model to assess lamellar signaling relevant to preferential weight bearing in the horse, The Veterinary Journal, 221, 62-67. https://doi.org/10.1016/j.tvjl.2017.02.005

3. Hutchins, D.R., McClintock, S.A., \& Brownlow, M.A. (1987). Use of flotation tanks for the treatment of seven cases of skeletal injury in horses, Equine Veterinary Journal, 19, 73-77.

4. https://doi.org/10.1111/j.2042-3306.1987.tb02588.x

5. van Eps, A., Engiles, S.J., \& Galantino-Homer, H. (2021). Supporting limb laminitis, Veterinary Clininics of North America - Equine Practice, 37, 657-668. https://doi.org/10.1016/j.cveq.2021.08.002

6. Orsini, J.A. (2012). Supporting limb laminitis: The four important 'whys', Equine Veterinary Journal, 44, 741-745. https://doi.org/10.1111/j.2042-3306.2012.00662.x

7. Schatzmann, U. (1998). Suspension (slinging) of horses: history, technique and indications, Equine Veterinary Education, 10, 219-223. DOI: 10.111/j.2042-3292.1998.tb00880.x

8. Bowman, K.F. (1995). Slinging Horses, Journal of Equine Veteterinary Science, 15, 152-154. DOI: 10.1016/S0737-0806(06)81847-2

9. Smith, W.N. (1981). Use of a flotation tank to sling horses and cattle undergoing surgery to the limbs, Australian Veterinary Journal, 57, 441-443. https://doi.org/10.1111/j.1751-0813.1981.tb05758.x

10. Wattle, O., Ekfalck, A., Funkquist, B., \& Obel, N. (1995). Behavioural Studies in Healthy Ponies Subjected to Short-term Forced Recumbency Aiming at an Adjunctive Treatment in an Acute Attack of Laminitis, Journal of Veterinary Medicine Series A, 42, 62-68. https://doi.org/10.1111/j.14390442.1995.tb00356.x

11. Steinke, S.L., Carmalt, J.L., \& Montgomery, J.B. (2021). Weight reduction and possible implications for the rehabilitation of horses with ambulatory difficulties, Equine Veterinary Education, 33, 152158. https://doi.org/10.1111/eve.13210

12. Steinke, S.L., Belgrave, L.J., \& Montgomery, J.B. (2019). Development of a novel harness system to aid in rehabilitation of horses, Comparative Exercise Physiology, 15, 385-391.

https://doi.org/10.3920/CEP180062

13. Montgomery, J.B., Steinke, S.L., Williams, A.C., \& Belgrave, L.J. (2019). Initial testing of a computerintegrated weight compensation system for rehabilitation of horses, Comparative Exercise Physiology, 15, 379-384. https://doi.org/10.3920/CEP180060

14. Clayton, H.M. (2016). Horse species symposium: Biomechanics of the exercising horse, Journal of Animal Science, 94, 4076-4086. DOI: 10.2527/jas.2015-9990

15. Ainla, A., Verma, M.S., Yang, D., \& Whitesides, G.M. (2017). Soft, Rotating Pneumatic Actuator, Soft Robotics, 4, 297-304. https://doi.org/10.1089/soro.2017.0017 
16. Sonar, H.A., \& Paik, J. (2016). Soft pneumatic actuator skin with piezoelectric sensors for vibrotactile feedback, Frontiers in Robotics and Al, 2, 1-11. https://doi.org/10.3389/frobt.2015.00038

17. Suh, C., Margarit, J.C., Song, Y.S., \& Paik, J. (2014). Soft Pneumatic Actuator skin with embedded sensors, 2014 IEEE International Conference on Intelligent Robots and Systems, 2783-2788. DOI: 10.1109/IROS.2014.6942943 https://ieeexplore.ieee.org/document/6942943

18. Dragon Skin 30, Smooth-On, Inc., 2020. [Online]. Available: https://www.smoothon.com/products/dragon-skin-30/. (Retrieved: 23-Jul-2020).

19. Malbrain, M., Hendriks, B., Wijnands, P., Denie, D., Jans, A., Vanpellicom, J., \& De Keulenaer, B. (2010). A pilot randomised controlled trial comparing reactive air and active alternating pressure mattresses in the prevention and treatment of pressure ulcers among medical ICU patients, Journal of Tissue Viability, 19, 7-15. https://doi.org/10.1016/j.jtv.2009.12.001

20. Pressure area care,Talley Group Ltd., 2018. [Online]. Available: https://www.talleygroup.com/category/pressure-area-care. (Retrieved: 28-Jul-2020).

21. McClintock, S.A., Hutchins, D.R., \& Brownlow, M.A. (1987). Determination of weight reduction in horses in flotation tanks, Equine Veterinary Journal, 19, 70-71.

22. https://doi.org/10.1111/j.2042-3306.1987.tb02586.x

23. Hayton, E., \& Sneddon, J.C. (2004). A descriptive study of stress fractures in competitive event horses in the UK, Equine and Comparative Exercise Physiology, 1, 233-238.

https://doi.org/10.1079/ECP200427

\section{Figures}
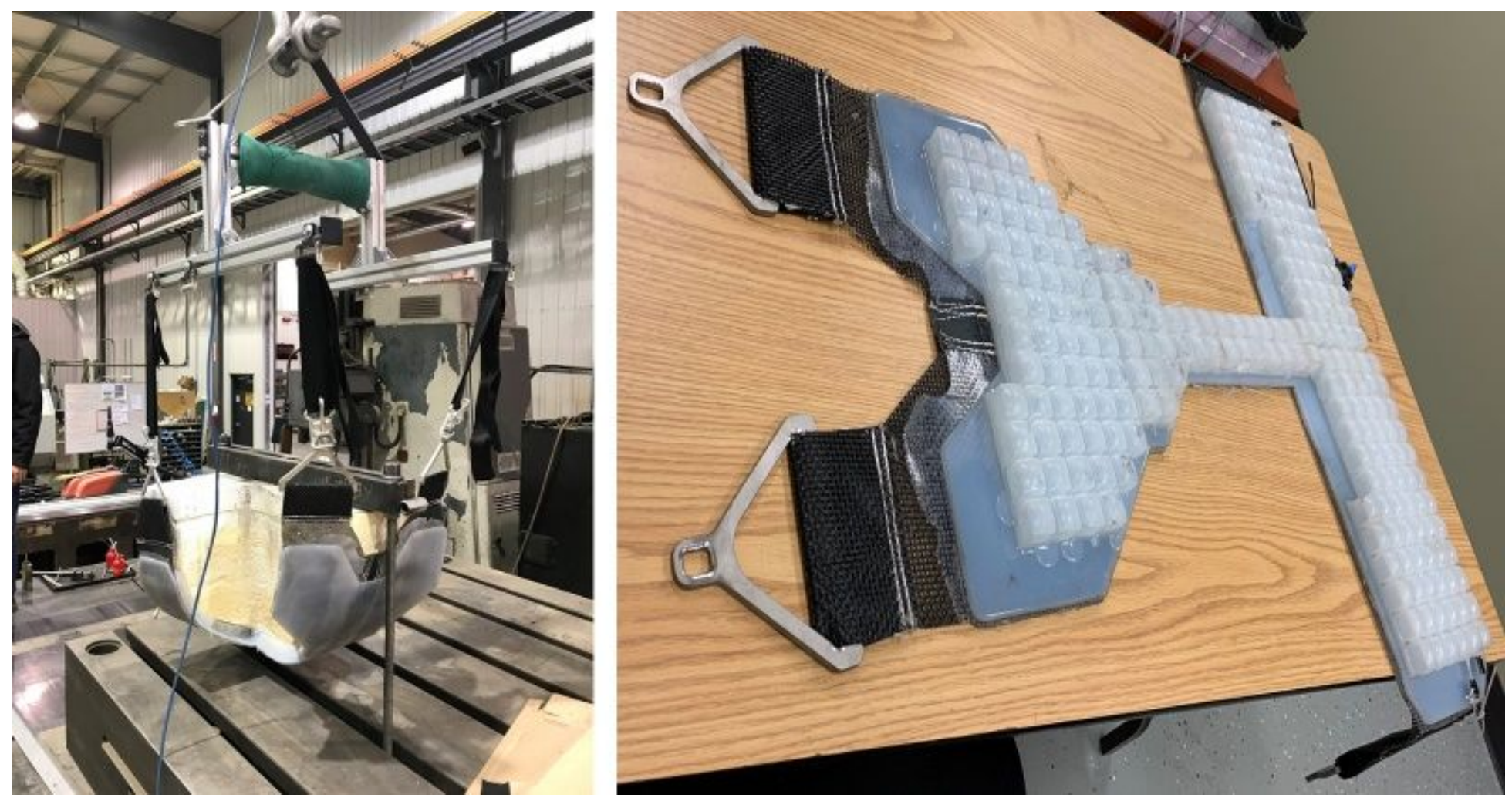
Figure 1

(A) Strength testing of prototype III (up to $227 \mathrm{~kg}$, > than the required $150 \mathrm{~kg}$ for safety margin). (B) Silicone air pockets attached to final breastplate prototype III.
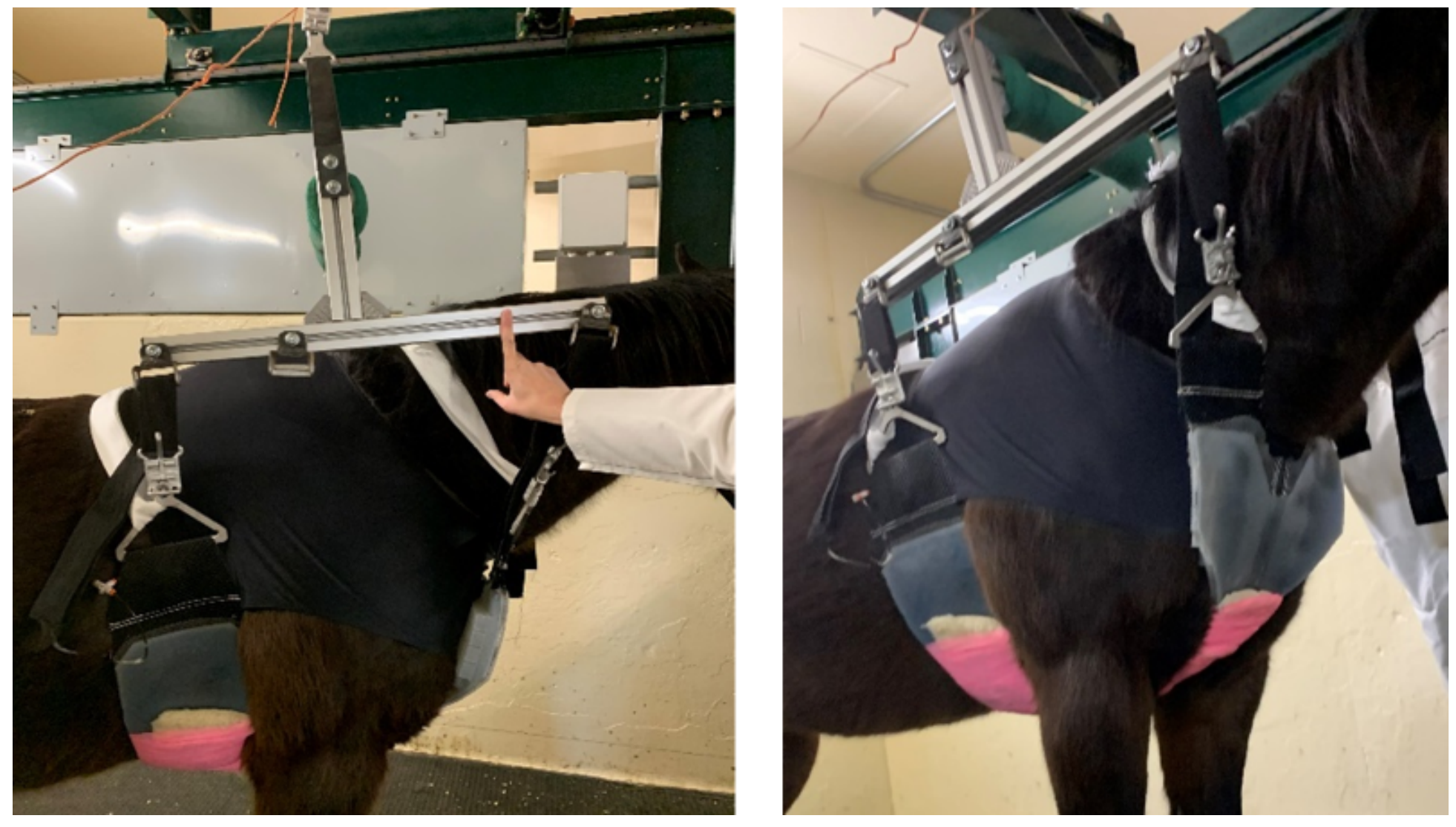

Figure 2

The first testing of Prototype III worn by the research horse and attached to the weight compensation lift via an $\mathrm{H}$ frame (indicated in $\mathrm{A}$ ). 

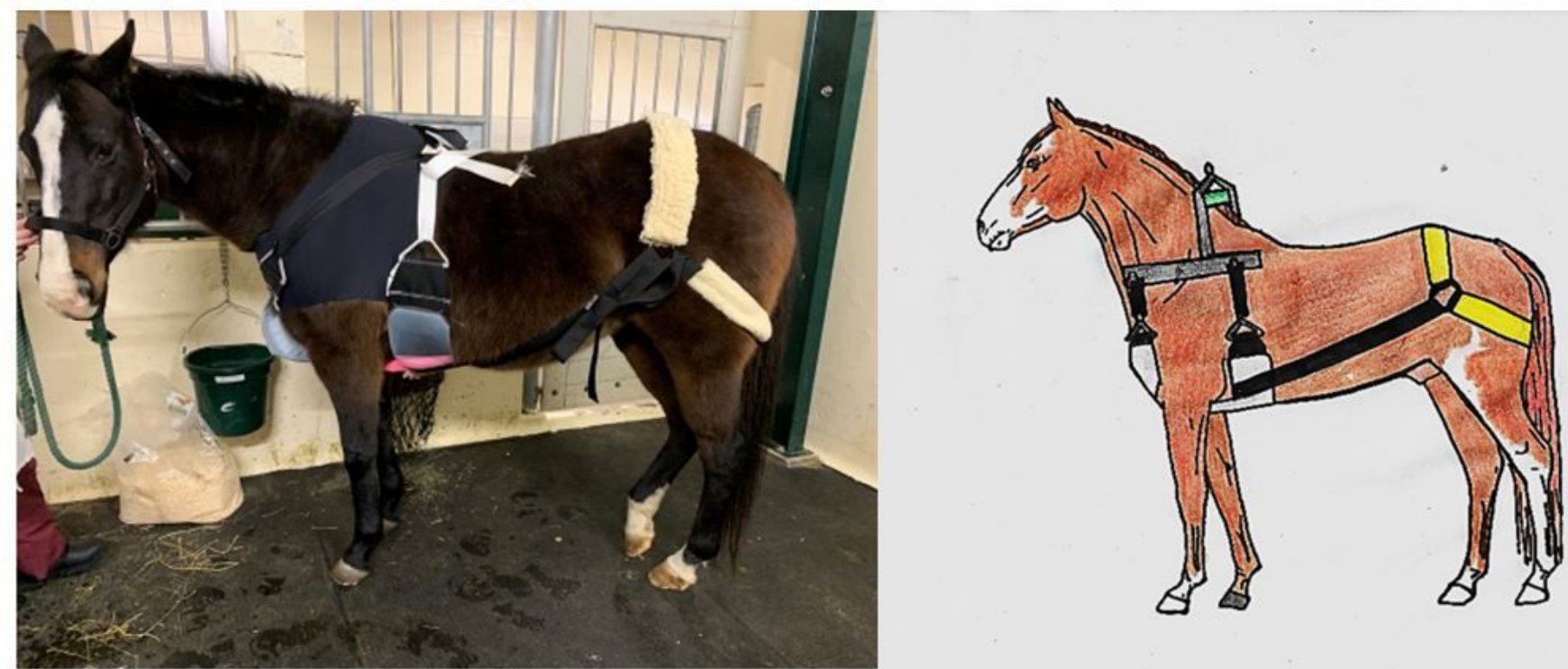

\section{Figure 3}

Research horse with final prototype III and drawing of third breastplate prototype design with a tail strap. The rehabilitation harness component was successfully tested to $50 \%$ weight reduction in the front limbs using a dynamic computer-controlled rehabilitation list, previously described in [12]. 